PEDAGOGIA : Jurnal IImu Pendidikan

\title{
ARAH PEMBELAJARAN ANAK CEREBRAL PALSY
}

\author{
Mimin Tjasmini*)1 \\ ${ }^{1}$ Dosen Departemen Pendidikan Luar Biasa, Fakultas Imu Pendidikan \\ Universitas Pendidikan Indonesia
}

\begin{abstract}
Anak Cerebral Palsy memiliki hambatan yang kompleks seperti : hambatan fisik dan motorik, kecerdasan intelektual, sosial emosi, hambatan visual, audio, kinestetik bahkan sensasi rasa. Area kerusakan di otak menyebabkan berbagai jenis anak CP seperti spastik, atetoid, rigid, ataxia, treamor dan tipe campuran.Pembelajaran bagi mereka harus memuat berbagai pengembangan kemampuan yaitu (1) pengembangan intelektual dan akademik, (2) membantu perkembangan fisik, (3) meningkatkan perkembangan emosi dan penerimaan diri anak, (4) mematangkan aspek social, (5) mematangkan moral dan spiritual, (6) meningkatkan ekspresi diri, dan (7) mempersiapkan masa depan anak.
\end{abstract}

Keywords : Cerebral Palsy, Pembelajaran

*) Dra. Mimin Tjasmini, adalah Jurusan Pendidikan Luar Bias a FIP UPI. 
PEDAGOGIA : Jurnal IImu Pendidikan

A. Latar Belakang Masalah

Berbagai hambatan yang dialami anak Cerebral Palsy menuntut banyak hal yang menjadi pertimbangan dalam pembelajaran mereka. Keragaman individu penyandang Cerebral Palsy dalam hal mobilitas, inte lektual, gangguangangguan lain dalam system saraf memberi pengaruh yang tidak kecil dalam membantu mereka belajar. Merujuk pada tujuan Pendidikan Nasional yaitu mencerdaskan kehidupan bangsa dan mengembangkan manusia seutuhnya, seperti manusia yang beriman dan bertaqwa terhadap Tuhan Yang Maha Esa dan berbudi pekerti luhur, memiliki pengetahuan dan keterampilan, sehat jasmani dan rohani, kepribadian yang mantap dan mandiri serta tanggung jawab kemasyarakatan dan kebangsaan.

Mencermati tujuan pendidikan di atas, sangatlah sulit bagi anak Cerebral Palsy untuk menggapai tujuan itu mengingat sangat idealnya tujuan pendidikan nasional yang ingin dicapai itu. Dari sisi mencerdaskan kehidupan bangsa saja, sebagian besar dari mereka tak mungkin bias mencapai criteria cerdas karena selain mereka terganggu mobilitasnya, juga terganggu kecerdasannya. Pernyataan ini sesuai dengan pendapat
Stephen dan Hawks (1983:420) yang tersurat dalam buku Educting Exceptional Children menyatakan ".....estimated that 40 to 60 percent of children with cerebral palsy were mentally retarded". Tuntutan kesehatan jasmani dan rohani pun akan mendapat kendala mengingat ada beberapa prasyarat untuk mencapai kondisi itu. Kepribadian yang mandiri serta tanggung jawab kemasyarakatan dan kebangsaan, dapat diwujudkan sekalipun implementasinya pasti berbeda dengan siswa pada umumnya.

\section{B. Pembahasan}

Sebelum mengetahui arah pembelajaran anak Cerebral Palsy, informasi penting yang harus diketahui termasuk:

\section{Konsep Anak Cerebral Palsy}

Untuk memahami anak Cerebral Palsy dibutuhkan informasi yang jelas mengenai mereka. Secara etimologis Cerebral Palsy berasal dari dua kata yaitu cerebral atau cerebrum yang berarti otak, dan palsy yang berarti kelayuhan atau lesi atau kerusakan pada otak yang bermanifestasi pada fungsi-fungsi tubuh yang dipersarafinya. Bagian 
PEDAGOGIA : Jurnal Ilmu Pendidikan

otak yang rusak yaitu pada pusat motorik di otak yaitu Gyrus Precentralis. Gyrus Precentralis terbagi lagi menjadi beberapa area diantaranya system Piramidalis dan Extrapiramidalis.

Kerusakan pada area tertentu memberikan tampilan jenis-jenis cerebral palsy. Beberapa symptom yang dapat kita lihat pada anak cerebral palsy yaitu adanya gangguan motorik (gerak), postur tubuh yang miring ke kiri atau ke kanan (skoliosis),tulang belakang melengkung ke belakang (kiposis), atau tulang punggung melengkung ke depan (lordosis). Diantara mereka banyak yang menga lami kesulitan dalam belajar, juga terdapat gangguan lain seperti gangguan persepsi visual, auditif, bahkan gangguan bicara. Kenyataan seperti itu diperkuat oleh pernyataan World Commission on Cerebral Palsy bahwa :

"Cerebral Palsy adalah suatu sindroma dimana terdapat gangguan terutama system motorik, sikap tubuh,pergerakan otot, dengan atau tanpa keterbelakangn mental, dapat disertai gejala saraf lainnya yang disebabkan disfungsi otak sebelum perkembangannya sempurna (Venusri Latief : 1987:3 ).

Berdasarkan type gangguan motoriknya Denhof:1976 dalam buku Exceptional Children (1983:329) menjelaskan bahwa: "Classification according to type of motor disabilitity typically includes the following catagories : Spasticity, Athetosis, Ataxia, Rigidity Cerebral Palsy, Tremor Cerebral Palsy, and Mixed Cerebral Palsy.

Selain katagori gangguan motoriknya, Denhof mengklasifikasi anak CP berdasarkan anggota gerak yang rusak yaitu: "Cerebral Palsy individuals falling into each class, may be summarized as follow: Hemiplegia, Diplegia, Quadriplegia, Paraplegia, Monoplegia, Triplegia, dan Double Hemiplegia".

2. Hambatan-hambatan Anak Cerebral Palsy

Sekalipun hambatan anak CP begitu kuas 
PEDAGOGIA : Jurnal IImu Pendidikan

dan kompleks bahkan pada awal mulanya diperkenalkan istilah CP disebut little's desease tetapi CP bukanlah suatu penyakit sekalipn banyak menimbulkan gangguan sebagaimana

dinyatakan

oleh

Cruickshank

dalam buku Exceptional Children (1982 : 330 ) yaitu :

"when the brain is demaged, sensory ability, cognitive function's and emotional

responsiveness as well as motor performances are ussually affected. A very high

proportion of children with $C P$ will be found to have hearing impairement's, visual

impairement's, perceptual

disorders, speech deefects, behavior disorders, mental retardation, or some combination of several of these handicapping conditions in addition to motor disability. They may also exhibit unpleasant

caracteristics such

as drooling or facial contortions".

a. Gangguan Motorik Gangguan motorik anak CP dapat berupa kesulitan berpindah tempat (mobilitas), bergerak dan berjalan. Hal ini karena kelumpuhan atau kekakuan dari salah satu anggota gerak bagian atas dan bawah.

Gangguan

koordinasi antara otot, tulang, persendian merupakan akibat kerusakan otaknya. Kerusakan pada system Piramidalis dan

ekstrapiramidalis

yang mengatur system motorik manusia, menyebabkan anak CP mengalami kekakuan, kelumpuhan ,gerakan-gerakan involunter yang tak dapat dikendalikan. Disaming itu anak CP ada yang berjalan terhuyunghuyung, pola jalan menggunting, tidak 
PEDAGOGIA : Jurnal Ilmu Pendidikan

ada keseimbangan, karena kerusakan terjadi pada otak kecil (Cerebellum).

Dengan gangguan motorik ini anak sulit melakukan aktvitas hidup sehari-hari di rumah dan sekolahBerkaitan dengan akademik, anak sulit untuk menulis dan berolah raga. Di rumah anak akan kesulitan untuk: makan, minum, mandi, ke toilet, berpakaian, menanggalkan pakaian dsb.

b. Gangguan Sensoris Luasnya kerusakan di otak berakibat pada system sensoris seperti; kelainan

penglihatan, pendengaran, perabaan, bahkan sensasi rasa pengecapan.

Gangguan

penglihatan

disebabkan

gangguan pada saraf periper yang mengatur pekerjaan bola mata. Gangguannya dapat berupa juling( Strabismus),

Astigmatis, dan kelainan mata lain yang disebabkan oleh tremor bola mata, yang menyebabkan bola mata bergerakgerak sehingga penglihatan menjadi tidak jelas.

c. Gangguan

Berbicara

Area Brocca yang menjadi pusat bahasa di otak yang ikut terganggu karena luasnya kerusakan di otak menyebabkan anak sulit memahami bahasa. Disamping sulit memahami bahasa, gangguan akan bertambah kompleks bila otototot mulut, lidah dan otot artikulasi lainnya terganggu, anak akan kesulitan untuk

berkomunikasi. Hal ini wajar dialami oleh anak CP karena otot-otot lidah, mulut, dan pipi dipesarafi oleh saraf periper di otak.

d. Gangguan

Kecerdasan

Seperti

diungkapkan oleh Stephen dan Hawks bahwa 40 sampai 60 
PEDAGOGIA : Jurnal Ilmu Pendidikan

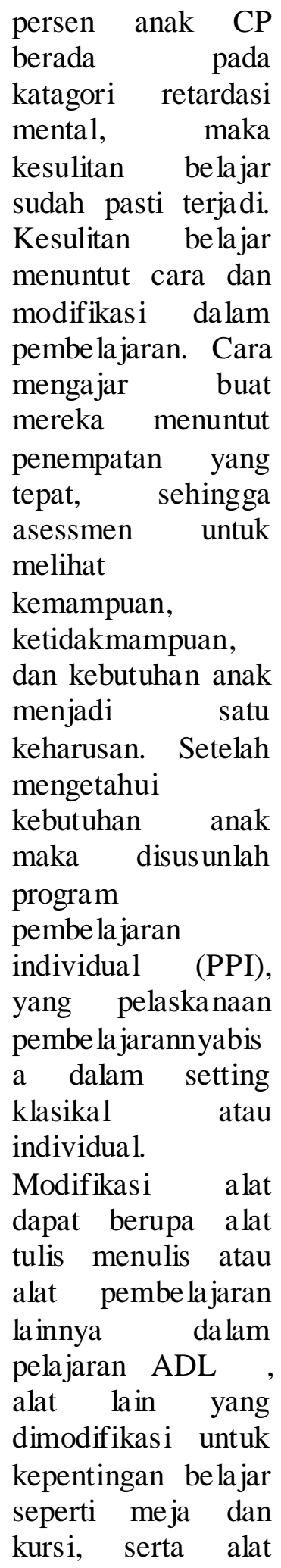

mobilitas di

sekolah.

e. Gangguan Emosi dan Penyesuaian

Sosial

Penyesuaian sosial anak Cerebral Palsy menjadi terhambat hubungan sosialnya mengingat, adanya hambatan yang menjadi sarat setiap orang untuk melakukan hubungan social . Persaratan yang dimaks ud seperti; keterampilan berkomunikasi, adanya kemampuan mobilitas, keberanian, dan kemauan untuk bergaul.

Hasil penelitian

Sawrey dan Telford, $\quad 1975$ dalam

Ortopedagogik

Anak Tunadaksa (Musjafak Assjari: 1995:71)

menyatakan bahwa:

"kecacatan yang terdapat pada diri anak, respond an sikap masyarakat mempengaruhi pembentukan pribadi anakanak cerebral 
PEDAGOGIA : Jurnal Ilmu Pendidikan

$$
\begin{aligned}
& \text { palsy secara } \\
& \text { umum, dan } \\
& \text { khususnya } \\
& \text { yang berkaitan } \\
& \text { dengan konsep } \\
& \text { dirinya". }
\end{aligned}
$$

3. Pembelajaran

Anak

Cerebral Palsy

Arah pembelajaran anak cerebral palsy diorientasikan pada adanya pengembangan dari berbagai hambatan - hambatan yang dimiliki menjadi lebih baik.Seorang pakar yaitu Connor (1975) dalam Musjafak Assjari (1995

mengemukakan bahwa :

$$
\begin{aligned}
& \text { sekurang } \\
& \text { kurangnya ada } \\
& \text { tujuh aspek yang } \\
& \text { perlu } \\
& \text { dikembangkan } \\
& \text { pada diri masing } \\
& \text { - masing anak } \\
& \mathrm{CP} \text { melalui } \\
& \text { pendidikan yaitu } \\
& \text { pengembangan } \\
& \text { intelektual dan } \\
& \text { akademik, (2) } \\
& \text { membantu } \\
& \text { perkembangan } \\
& \text { fisik, (3) } \\
& \text { meningkatkan } \\
& \text { perkembangan } \\
& \text { emosi dan } \\
& \text { penerimaan diri } \\
& \text { anak, } \\
& \text { mematangkan }
\end{aligned}
$$

aspek social, (5) mematangkan moral dan spiritual, meningkatkan ekspresi diri, dan (7) mempers iapkan masa depan anak.

a. Pengembangan inte lektual akademik Sebagaimana diungkapkan oleh Stephn dan Hawks bahwa kondisi anak Cerebral Palsy sebagian besar mengalami retardasi mental, ini berarti bahwa

pengembangan akademis berkaitan dengan kurikulum diarahkan pada kurikulum yang fleksibel.

Kurikulum fleksibel dimaknai sebagai kurikulum yang mendekati anak, dan bukan anak yang mengejar kurikulum. Dengan kata la in kurikulum yang harus menyesuaikan dengan kebutuhan anak. Yang paling penting dan mendasar dalam 
PEDAGOGIA : Jurnal Ilmu Pendidikan

pengembangan

inte lektual dan akademik anak haus diberi kepercayaan bahwa dia mampu untuk melakukan tugas. Jika anak selalu kecewa karena tidak mampu mengerjakan tugas tertentu anak akan mengalami

kekecewaan dan akhirnya menuntun anak menjadi trauma dalam belajar.

b. Membantu

perkembangan fisik Seperti kita ketahui bersama bahwa kondisi fisik anak Cerebral Palsy berbeda dengan anak pada umumnya.

Kemampuan fis ik dan motorik yang masih ada pada anak perlu dikembangkan dan dipe lihara agar tidak terjadi kondisi fis ik yang memburuk, misalnya terjadinya kontraktur pada persendian. Latihan - latihan tertentu berkaitan dengan kemampuan fis ik yang masih ada bila tidak ada profesi lain seperti tenaga medis dan para

medis maka guru berperan dalam membantu hal - hal yang masih mungkin dilakukan. Pernyataan ini sesuai dengan pendapat Verhaaren dan Connor (1981) dalam Exceptional Children (1982:330) menyatakan bahwa: "teaching the child who is cerebral Palsied demands competance in many aspects of special education and experience in working with a variety of handicapping conditions in a multi disiplinary setting"

c. Meningkatkan perkembangan emosi dan penerimaan diri anak Para ortopedagog dan profesi lain seperti psikolog, psikiater anak berkolaborasi 
PEDAGOGIA : Jurnal Ilmu Pendidikan

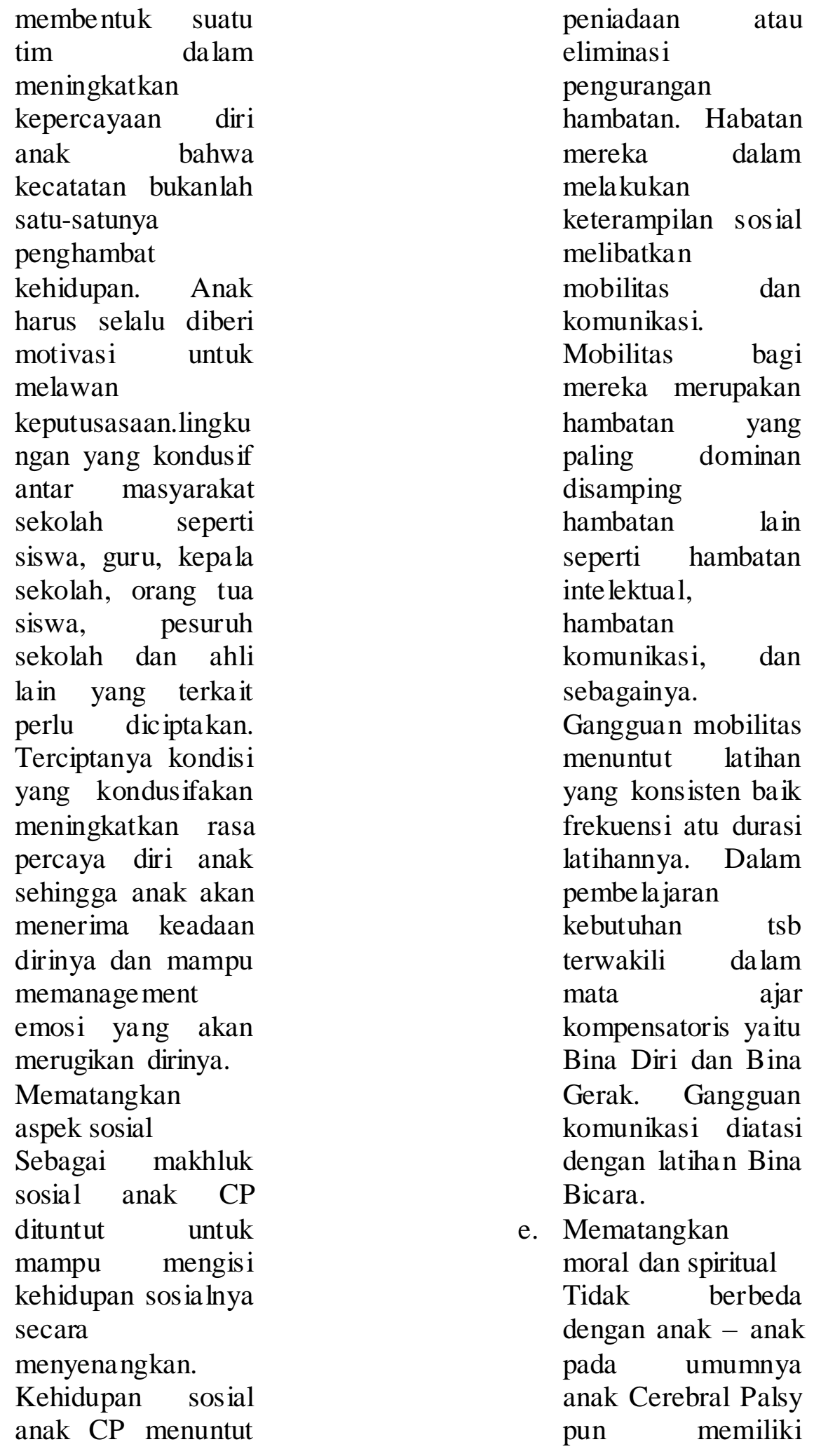


PEDAGOGIA : Jurnal IImu Pendidikan

kebutuhan akan pengembangan

moral dan spiritualnya.norma

- norma kehidupan dapat dipelajari anak lewat contoh contoh yang diperlihatkan oleh guru dibandingkan dengan te ori - teori yang disampaikan di kelas. Contoh contoh yang baik dan datang dari peraturan agama berangsur -angsur akan diimitasi oleh anak yang pada akhirnya anak akan memiliki aspek moral dan spiritual yang diharapkan.

f. Meningkatkan ekpresi diri

Anak Cerebral Palsy dengan berbagai hambatan dan keterbatasan gerak membutuhkan

keterampilan

keterampilan

khusus atau

keterampilan dasar kehidupan dalam meningkatkan

ekspresi dirinya.

Sekolah

bertanggung jawab membawa anak untuk mencapai ekspresi diri ini melalui berbagai

kegiatan seperti kegiatan pramuka, olahraga, lomba kreativitas seni, membuat

keterampilan dan produk - produk lain sebagai hasil kreativitas anak perlu ditonjolkan. Sekolah harus mengikutsertakan semua anak, karena tujuan dari pengikutsertaan dari suatu lomba bukanlah

kemenangan

melainkan

keikutsertaan anak atau partisipasi anak dalam suatu lomba. Kepercayaan dari sekolah / guru mengikutsertakan anak pada suatu lomba merupakan wujud ekspresi diri dari seorang siswa.dengan

berekspresi diri akan menimbulkan perasaan senang pada diri anak.

g. Mempersiapkan masa depan anak Mempersiapkan masa depan anak mempunyai arti yang sangat luas karena melibatkan hal - hal yang harus 
PEDAGOGIA : Jurnal IImu Pendidikan

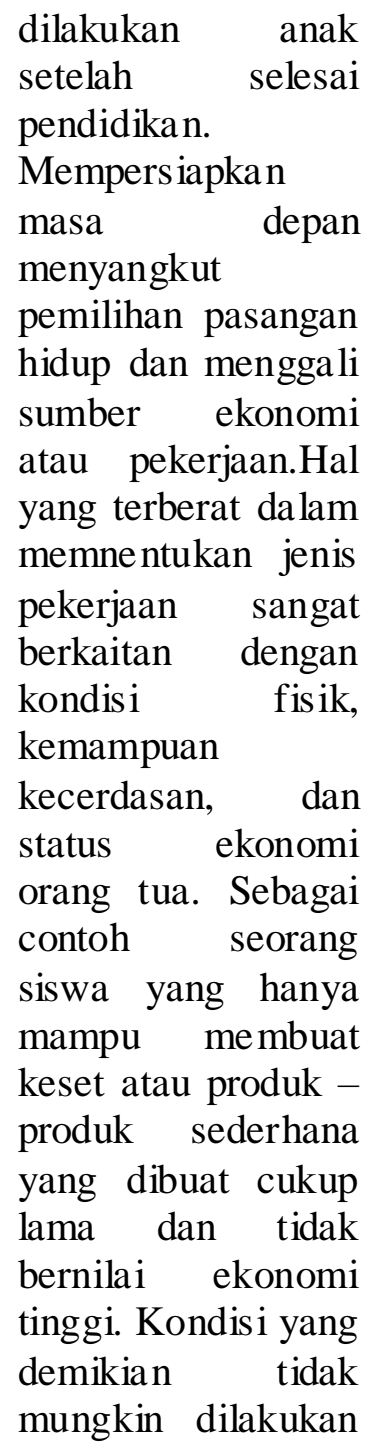

$$
\begin{array}{lr}
\text { oleh seorang } & \text { siswa } \\
\text { yang } & \text { status } \\
\text { ekonominy } & \text { mapan. } \\
\text { Sekolah } & \text { harus } \\
\text { mengupayakan } & \\
\text { adanya } & \text { Sheltered } \\
\text { workshop } & \text { untuk } \\
\text { menaungi } & \text { proses } \\
\text { pembuatan } & \text { produk } \\
\text { sampai pemasaran } \\
\text { produk. }
\end{array}
$$

C. Daftar Pustaka

A Mus jafak (1995). Ortope dagogik Anak Tuna Daksa. Jakarta : Departemen

pendidikan dan kebudayaan.

Hallahan dan Kaufman (1982).Exceptional Children. USA : Prentice Hall of Canada, Ltd Toronto.

Kirk and Gallagher (1983). Educating Exceptional Children. USA : Houghton mifflin company.

Latif Venusri (1987). Bandung : Pikiran Rakyat. 